ion to students, and often an absolute hindrance to the acquisition of a good English style.

3. Throughout the entire course of a pupil's studies, from the time he can construct a simple sentence to the time he leaves the highest grade, there should be constant and rigorous drill in the writing of English. This part of the instruction is by far the most important, and is, at the same time, the part most frequently neglected. The writer has already published his views regarding the proper methods to be pursued in the teaching of English composition, and will not, therefore, go into that subject in this paper. ${ }^{1}$ It is sufficient to say, in general terms, that all instruction in English composition should have con stantly in view the immediate capabilities and needs of the students. It is no uncommon occurrence to have students in the lower classes of a college complain that they are asked to write upon subjects much simpler than those given in the high schools. Students who have been stringing together a lot of senseless verbiage on 'Sunshine and shadow,' ' True greatness,' 'Heroism,' 'Honesty,' and the like, cannot see why they should be asked to descend to the trivial matters of every-day life, and to a discussion of subjects about which they know something. Yet one composition written on a familiar subject, composed with reasonable care, and then carefully and sympathetically criticised by the teacher, is worth a dozen perfunctory affairs, hurriedly written, upon subjects entirely beyond the experience or knowledge of the pupil. Careful and conscientious work in English composition would afford the best possible basis for future studies in all fields. With this should go, if possible, a reasonable familiarity with good writers, in order that the vocabulary of the pupil might be enlarged, and models of good and wholesome English be constantly presented.

In conclusion, it is only just to say that the charge of neglecting the proper study of English does not lie at the door of the preparatory schools alone. It is only within very recent years that English has begun to receive a fair share of attention in the colleges and universities. The tendency of modern education is toward the practical. It is beginning to be seen that the most useful weapon in the hands of any scholar is a thorough and practical knowledge of his own language. This conviction is arousing our colleges to better methods of work in this department, and is, in consequence, making necessary better preparation in the secondary schools. This preparation they can and should provide.

ERNEST W. HUFFCUT.

1 See the New England journal of education for December and January.

\section{SCANDINAVIAN STUDIES IN THE UNITED} STATES.

CoMPLAINT has been made by many scholars that the study of the Scandinavian languages is almost entirely neglected in our colleges and universities, and that the general public is not alive to the importance of this study. Of the justice of the complaint there can be no doubt; but that the neglect is continually becoming less and less, it is my object to prove in this short paper. As no complete account of the Scandinavian movement in our colleges has ever been written, and as it is necessary, in order to arrive at a logical conclusion, that there should be a clear understanding of this movement, it may not be amiss if I preface my remarks with a brief sketch of the origin and development of Scandinavian studies in the United States. Though I have taken great pains to make the account complete, it is possible that some colleges may not receive the notice due them. Only college instruction will be discussed, the consideration of the purely literary side of the question being necessarily omitted.

To the University of the city of New York is due the credit of founding the first chair of the Scandinavian languages and literature. In 1858, Rev. Paul C. Sinding of Copenhagen was appointed the first professor in this department, and occupied the position, with honor to himself and the university, till his resignation in 1861. Professor Sinding's work had to do chiefly with Danish history and literature ; and of the interest his work awakened in New York, we may judge from the fact that his 'History of Scandinavia' ran through seven editions in a few years. Since Professor Sinding's resignation, the chair has remained unoccupied.

In the same year that the study of the Scandinavian languages was abandoned in the University of the city of New York, the Norwegian Luther college was founded at Halfway Creek, Wis., and in 1862 was removed to Decorah, Io., where it is still lozated. It "owes its origin to the growing demand for educated men who could preach the Word of life to the rapidly increasing Norwegian population of this country." Luther college is, then, the first purely Scandinavian college in America. The instruction has always had a distinctively Norwegian tendency, and many of the text-books are printed in that language. The faculty and the students are almost entirely of Norwegian birth or parentage, and the Norwegian language and literature are studied through the whole college course.

On the opening of Cornell university in 1868, Willard Fiske was appointed professor of the North European languages, and instruction was 
offered to students in Icelandic and Norwegian. In 1877, H. H. Boyesen was appointed assistant professor in the same department. Professor Boyesen resigned in 1880,-and Professor Fiske in 1883 , and since that time the department has been without a head.

In the same year that Cornell was founded, 1868, the example set by Luther college was followed by a Swedish colony in Illinois. The emigration from Sweden to this country had, in 1868 , assumed such large proportions, that a Swedish theological seminary was established in Galesburg, IIl. Its object was the preparation of young men from the Methodist Episcopal church for the ministry. The seminary, which in 1882 was moved to Evanston, Ill., and united with the North-western university, is at present in a flourishing condition : "The course extends over three years, and the Swedish language and literature are studied throughout." In 1885 the Norwegian and Danish theological school was founded at the same university, and with similar aims. These two schools, together with Luther college, though quite unimportant from a philological stand-point, afford us ample proof of the practical side of the question as to the status of Scandinavian instruction in the United States.

In 1869, R. B. Anderson was appointed instructor in modern languages at the University of Wisconsin, offering a course in Icelandic, among others, - the first ever given in the United States. Six years later, Mr. Anderson was promoted to the position of professor of Scandinavian languages, which he continued to hold till his resignation in the autumn of 1883 . During the remainder of that school-year, J. E. Olson taught a class of ten, in Icelandic. The following year, Mr. Olson was appointed instructor in the Scandinavian languages. At present, Mr. Olson has a class of thirteen members in Norse. Of the demand for instruction in this department, we may judge from the fact that there has been application from six students to begin a class in Icelandic. The Scandinavian languages were originally offered as optionals only ; but soon after the creation of a separate department, Norse and Icelandic were offered as optionals in freshman and sophomore years, and as electives in junior, and, later still, also in senior years.

Next in order of time comes Columbia college, at present the only eastern college in which the Scandinavian languages can be studied. Instruction in Danish was first given by C. Sprague Smith, professor of modern languages during the winter of 1880-81, and in Swedish during the winter of 1882-83. In the fall of 1883 , W. H. Carpenter, Ph.D., was appointed instructor in
German, Icelandic, Danish, and Swedish, having classes that year, of three each, in Icelandic and Danish. During the last winter, Dr. Carpenter had classes in Icelandic and Danish ; Professor Boyesen, one in Swedish; and Professor Smith delivered a course of lectures on Danish and Swedish literature, with reading of texts. For the present year, in addition to the preceding courses, Professor Boyesen offers a seminar in contemporary Norwegian and Danish literature, with lectures and conversation in Norwegian.

Still another western institution, the University of Nebraska, offers this year, for the first time, facilities for Scandinavian work; A. H. Edgren, Ph.D., a native-born Swede, professor of Sanscrit and modern languages, being the instructor.

Such is the list, as complete as possible, of the colleges in the United States which have at any time offered instruction in the Scandivavian languages. In connection with the subject, it may not be amiss to mention some courses of lectures on Scandinavian literature, other than academic, that have been delivered in this country. Prof. R. B. Anderson has lectured at the Peabody institute, Baltimore, and in different cities in Indiana; Professor Boyesen, before the Lowell institute, Boston, and at Columbia college, 1886. In 1881-82, Y. Theo. Dippold, Ph.D., lectured on the Niebelungen Lied in Boston and Cambridge : and in 1882, Dr. Carpenter delivered a course of twelve lectures on Old Norse literature at Johns Hopkins university.

The question as to the profit accruing from the study of the Scandinavian languages naturally presents itself. The well-worn arguments that have been used so much of late by the opponents and defenders of the old-fashioned system of Latin, Greek, and mathematics, may many of them be used with equal force in arguing this question. If the mental discipline furnished by the study of Icelandic be as great as that furnished by the study of Latin and Greek, if the culture of the old Norsemen give as profitable food for reflection as does the culture of the Greeks and Romans, then Icelandic wins the day, and gains a right to a place in every college course. This paper is intended mainly as an account of what has been done in the past, rather than an argument for what shall be done in the future, so that I shall not attempt a support of my position, when I make the claim that in each of these particulars Icelandic equals both Greek and Latin. I say nothing of the national significance of Icelandic studies to all who call themselves Anglo-Saxons, though, in the opinion of many, this alone is enough to offset any possible advantage the older tongues may possess. But I wish to say a few 
words on the practical advantage of the study of the Scandinavian languages.

$$
\checkmark
$$

We of the east can scarce realize the part the Scandinavian plays in the west : books and newspapers are printed for him in his own language ; ministers preach the gospel to him in his own tongue; his presence is felt everywhere, save in the university and the college. A population of 107,768 Scandinavians lives in Minnesota, and there is not a college in which the parent tongues of this great mass of perple can be studied. But in order to give a clearer idea of the extent of the Scandinavian settlements in the west, I have taken a few tables from the U. S. census for 1880 (vol. i. pp. 465 and 261):-

\begin{tabular}{|c|c|c|c|c|c|}
\hline & 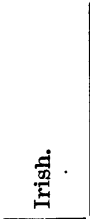 & 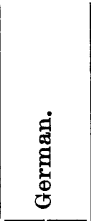 & 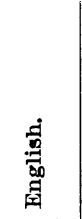 & 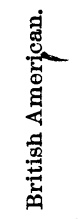 & శ్ \\
\hline Minnesota......... & 25,942 & 66,592 & 9,598 & 29,631 & 107,768 \\
\hline Wisconsin......... & 41,907 & 184,328 & 30,268 & 28,965 & 66,284 \\
\hline Illinois.............. & 117,343 & 235,786 & 60,012 & 34,043 & 65,414 \\
\hline Iowa.............. & 44,061 & 88,268 & 25,550 & 21,097 & 46,046 \\
\hline
\end{tabular}

That is, in Minnesota the Scandinavians outnumber any other two foreign nationalities; in Wisconsin they are outnumbered by the Germans alone; in Iowa they also stand second, and in Illinois third, in the proportion of foreign-born inhabitants. If we compare the percentage of Scandinavians with that of French, we find still more startling figures :-

\begin{tabular}{c|c|c}
\hline \hline & Scandinavian. & French. \\
\hline 1850 & $\cdot 0.80$ & 2.41 \\
1860 & 1.75 & 2.66 \\
1870 & 4.34 & 2.09 \\
1880 & 6.59 & 1.60 \\
\hline
\end{tabular}

What the percentage of Scandinavians in this country will be in 1890 , we can surmise from these figures. That it is increasing with as great rapidity as ever before, is very probable.

And it is this great people whose language and literature are considered of such slight importance that in only three of our. great colleges is any attention paid to their study. There are more Scandinavians in the United States than French, and there is not a college in the country in which French is not studied. It is true that the Scandinavian lan- guages are but little used on the continent; but no one can depreciate a language that counts among its great names H. C. Andersen, Adam Oehlenschläger, H. C. Oersted, Karl von Linné, Björnstjerne Björnsen, Ibsęn and Jonas Lie. Such a language deserves study for its own merits.

Yet a word on the three Scandinavian theological schools. The only medium by which the non-English-speaking Scandinarians can be reached, and taught to become good citizens, is by -men of their own race and tongue, who must be specially trained for this work. The three Scandinavian colleges that have been established for this purpose have done and are doing good work in their own way; but unfortunately their way is not our way; in fact, the views of the Scandinavian religious bodies are directly opposed to every thing distinctively American. Instead of trying to Americanize the Scandinavian youth of the west, these missionaries do all they can to keep their charges in their present condition. They do not teach them evèn to use the English language, but rather encourage, intentionally or not, the survival of a foreign language on American soil. The Scandinavian courses in our western colleges should be intended, not only to teach Norwegian and Swedish to Americans, but also English to Norwegians and Swedes. Those working as spiritual or secular teachers among the Scandinavians, should use their knowledge of the two tongues to increase and encourage the adoption of English as the natural means of communication of this great population of ours. It may seem inconsistent to advocate the study of a language as a means of its own destruction, but in actual working this plan will prove to be a success.

Daniel Kilham Dodge.

A MAP of central Africa, based on the latest information, is now nearly ready, and will be published in an early number of Science. This will be the most accurate map of that region yet published in America, and will be the only American map which will enable readers to follow the journey of Stanley to the relief of the lost Egyptian army. 